\title{
Methods for Predicting Remaining Life of Concrete in Structures
}

James R. Clifton

James M. Pommersheim*

Building and Fire Research Laboratory

Gaithersburg, Maryland 20899

*Bucknell University

Lewisburg, PA 17837

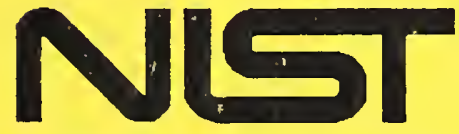

United States Department of Commerce Technology Administration

National Institute of Standards and Technology 



\section{Methods for Predicting Remaining Life of Concrete in Structures}

James Clifton

James Pommersheim

November 1992

Building and Fire Research Laboratory

National Institute of Standards and Technology

Gaithersburg, MD 20899

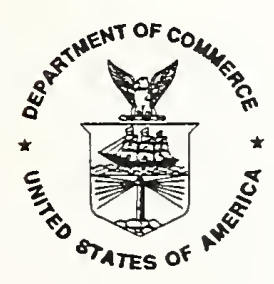

U.S. Department of Commerce

Barbara Hackman Franklin, Secretary

Technology Administration

Robert M. White, Under Secretary for Technology

National Institute of Standards and Technology

John W. Lyons, Director 


\begin{abstract}
The ability to predict the remaining life of concrete structures is becoming increasingly important as the nation's infrastructure ages. Decisions on whether to repair or to demolish structures may depend on the estimated remaining life. Little attention has been given to developing methods for predicting remaining service lives, with most of the reported work dealing with corrosion of concrete reinforcement. These methods primarily involve the use of mathematical models and life-time extrapolations based on corrosion current measurements.

Predicting remaining service life usually involves making some type of time extrapolation from the present state of the concrete to the end-of-life state. The application of the time order concept in making time extrapolations is described in this report. Also, ways to determine the value of $\mathrm{n}$ (time order) in the time function $\mathrm{t}^{\mathrm{n}}$ of degradation rate relationships are given. Use of the time order approach is demonstrated for $n=1 / 2,1$, and 2 . Ways to apply the approach to cyclic processes and multi-degradation processes are also discussed.
\end{abstract}

Situations may be encountered in which the remaining service life of concrete can only be estimated by predicting its original life using a service-life model. Such a situation could arise where the concrete can not be inspected or samples taken, due to its inaccessibility or to potential serious hazards involved with its inspection. An approach for applying this method is discussed.

Keywords: building technology, concrete, corrosion, diffusion, service life, reinforcement, reaction controlled, remaining service life, time order. 
Table of Contents

Page

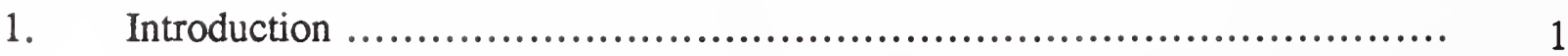

2. Review of Methods for Predicting Service Life of Concrete .................. 1

2.1 Modeling Approach ................................................... 1

2.2 Corrosion Measurements ........................................ 3

3. Prediction Based on Extrapolation ..................................... 5

3.1 Empirical Extrapolation .......................................... 5

3.2 Time Order Concept ................................................ 5

3.3 Value of $\mathrm{n}$........................................................... 6

3.3.1 Theoretical Values of $\mathrm{n}$ for Diffusion and Reaction Control .... 6

3.3.2 Values of $n$ Based on Mathematical Models .................... 10

3.3.3 Value of $n$ Obtained from Accelerated Degradation Studies .... 11

3.4 Example of Application .......................................... 12

3.5 Dealing with Cyclic Degradation Processes ........................... 13

3.6 Applicability to Multi-Degradation Porcesses ......................... 13

4. Predictions Based on Estimating Original Service Life ....................... 13

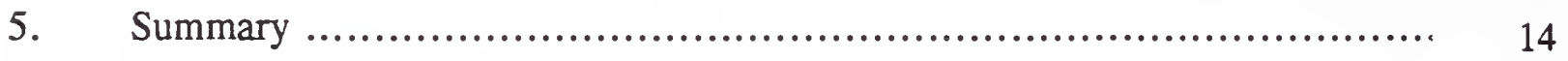

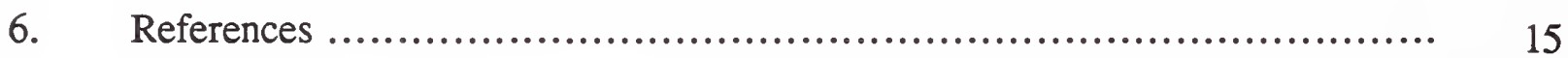

List of Tables

Page

Table 1. Values of $n$ Obtained from Models [2] .................................... 11 


\section{List of Figures}

$\underline{\text { Page }}$

Figure 1. Schematic of Conceptual Model of Corrosion of Steel

Reinforcement in Concrete [4].......................................

Figure 2. Effect of Corrosion on the Diameter $(\Theta)$ and Cross Section of Steel Reinforcing Bars, with Diameters of $10 \mathrm{~mm}$ and $20 \mathrm{~mm} \mathrm{[14]} \mathrm{......}$

Figure 3. Reduction in Bending Moment Capacity of Concrete Beam by Corrosion of Reinforcing Steel [4]

Figure 4. Relationship Between Corrosion Intensity (current) of Steel

Reinforcement and Concrete Environment [16]

Figure 5. A. Schematic of Predicting Remaining Service Life by Extrapolation:

B. Effect of Neglecting Induction Period on Predicting

Remaining Life

Figure 6. Schematic of Conceptual Model of Moving Interface Between Degraded and Undegraded Concrete

Figure 7. Degradation Versus Time Relationships for $\mathrm{n}=1 / 2,1$ and $2 \ldots$

Figure 8. Determination of Value of $n$ Based on Plotting eq. (25) ............ 



\section{INTRODUCTION}

The ability to predict the remaining life of concrete structures is becoming increasingly important as the nation's infrastructure ages. For example, decisions on whether to relicense nuclear power plants will depend on consideration of several factors related to their further operation, including predictions of remaining service lives [1,2]. Predictions of remaining life also have been used in analyzing the cost-effectiveness of different repair or rehabilitation strategies. Hookham [3] used estimates of the remaining service life of an ore dock constructed in 1909 in planning rehabilitation strategies. In a sense, every inspection gives at least a qualitative life prediction, e.g., whether the structure needs repair or has adequate structural integrity to remain in-service until at least the next inspection.

Methods for predicting remaining service life usually involve the following general procedures: (1) determining the condition of the concrete; (2) identifying the cause(s) of concrete degradation; (3) defining the condition constituting end-of-life (EOL) of the concrete; and (4) making some type of time extrapolation from the present state of the concrete to the EOL state. This report first reviews reported methods for predicting the remaining service life of concrete and then discusses the time order method for making time extrapolations.

\section{REVIEW OF METHODS FOR PREDICTING SERVICE LIFE OF CONCRETE}

Most of the reported work on predicting service lives of concrete structures have dealt with corrosion of concrete reinforcement, reflecting the magnitude and seriousness of corrosion problems.

Two major approaches which have been pursued are the use of models and the use of corrosion rate measurements. These approaches are based on the conceptual model described by Tuutti [4], in which corrosion starts after the end of an initiation period followed by a propagation period of active corrosion (Fig. 1). The initiation period involves the transport of chloride ions to the depth of the reinforcing steel at a sufficient concentration (threshold concentration) to depassify the reinforcing steel, by carbonation reducing the $\mathrm{pH}$ of the pore liquid in contact with the steel, or the combination of chloride ingress and effects of carbonation. Corrosion occurs in the propagation period, with its rate being controlled by the rate of oxygen diffusion to the cathode, resistivity of the pore solution, and temperature. Often it is assumed that the induction period is much longer than the propagation period and the end of the induction period is used for predicting service lives. This assumption is reasonable, unless the concrete is water-saturated, under which condition the propagation period will be the overall rate controlling period $[5,6]$.

\subsection{Modeling Approach}

Browne [7] used a diffusion-based model for predicting the remaining service life of inservice reinforced concrete structures exposed to chloride ions. It only considers the 
initiation period, and thus assumes that the diffusion of chloride ions is the rate controlling process. The steps in making predictions are:

(1) Samples are obtained from a concrete structure at different depths from the concrete surface and their chloride contents are determined.

(2) The following equation is used to obtain values of $C_{o}$ and $D_{c l}$ :

$$
C(x, t)=C_{o}\left[1-\operatorname{erf}\left(x / 2\left(D_{c l} t\right)^{1 / 2}\right)\right.
$$

where $\mathrm{C}(\mathrm{x}, \mathrm{t})$ is the chloride concentration at depth $\mathrm{x}$ after time $\mathrm{t}$, for a constant chloride concentration of $C_{o}$ at the surface; $D_{c l}$ is the chloride ion diffusion coefficient; and erf is the error function.

(3) Once the values of $\mathrm{C}_{o}$ and $\mathrm{D}_{\mathrm{cl}}$ are obtained, then the chloride ion concentration at any distance from the surface, at any given time, can be calculated.

(4) A chloride ion concentration of $0.4 \%$, based on mass of cement, is used by Browne as the threshold value. The time to reach the threshold concentration at the depth of the reinforcing steel gives the remaining service life.

Hookham [3] used two empirical models described by Vesikari [8] for predicting the remaining service life of an ore dock constructed in 1909. The "carbonation model" has the following formulation:

$$
\mathrm{t}_{\mathrm{c}}=\mathrm{L} / \mathrm{R}_{\mathrm{c}}
$$

where $t_{c}$ is the time to full cover carbonation, $L$ the remaining uncarbonated cover, and $R_{c}$ is the rate of carbonation. At the dock, the rate of carbonation, assuming linear diffusion, was calculated to be $0.028 \mathrm{~cm} / \mathrm{y}$. L was estimated to be $0.95 \mathrm{~cm}$. Using equation no. 2, the time-to-full carbonation was calculated to be approximately 34 years.

Prediction of remaining service life with respect to chloride attack was modeled using the relationship:

$$
\mathrm{t}_{2}=\mathrm{k}_{\mathrm{c}} * \mathrm{k}_{\mathrm{e}} * \mathrm{CR}^{2}+\mathrm{k}_{\mathrm{a}} * \mathrm{CR}
$$

where $t_{2}$ is the service life in years, CR is the thickness of concrete cover, $k_{c}$ the quality coefficient of the concrete, $k_{e}$ is the coefficient of environment, and $k_{a}$ is the coefficient of active corrosion. Based on the report by Vesikari [6], values of 7.59, 0.85 , and 4.0 were used for $k_{c}, k_{e}$, and $k_{a}$, respectively. CR was set equal to $L$ of the carbonation model $(0.95$ $\mathrm{cm})$. The predicted remaining life was 9.6 years. 
Another approach for predicting the remaining service life of concrete when carbonation is the major deleterious process is to use the square root time function [9]. The depth of carbonation, $x_{c}$, is given by:

$$
\mathrm{x}_{\mathrm{c}}=\mathrm{k}_{\mathrm{d}} \mathrm{t}^{1 / 2}
$$

By measuring the depth of carbonation in concrete and the age of the concrete $(t), k_{d}$ can be determined. The time for carbonation to reach the reinforcing steel can then be predicted by setting $x_{1}$ equal to the depth of the concrete cover over the reinforcement. In a damp environment, equation (4) may be conservative as the rate of carbonation could be much less than that predicted when the concrete pores are unsaturated [10]. Pocock [11] discussed the application of this relationship in predicting the remaining service life of concrete in nuclear power facilities. This method only considers the initiation period.

\subsection{Corrosion Measurements}

The measurement of corrosion currents of steel reinforcement in concrete have been used by both Andrade and co-workers [12-14] and by Clear [15] in estimating the remaining service life of reinforced concrete in which corrosion is the limiting degradation process. Both used the polarization resistance technique to measure corrosion currents.

Andrade modeled corrosion currents for estimating the remaining service life. Her model considers reduction in steel section as the significant consequence of corrosion, instead of cracking or spalling of the concrete.

The corrosion current was converted to reductions in the diameter of reinforcing steel by the relationship:

$$
\Theta(t)=\Theta_{i}-0.023 * i_{\text {corr }} * t
$$

where $\Theta(t)=$ the rebar diameter at time $t(\mathrm{~mm})$,

$\Theta_{i} \quad=$ the initial diameter of the rebar $(\mathrm{mm})$,

$i_{\text {cor }}=$ the corrosion rate $\left(\mu \mathrm{A} / \mathrm{cm}^{2}\right)$,

$\mathrm{t}=$ the time after the beginning of the propagation period (years), and

$0.023=$ the conversion factor of $\mu \mathrm{A} / \mathrm{cm}^{2}$ into $\mathrm{mm} /$ year.

The results were converted into service predictions by modeling the effects of reduction in cross section of the reinforcement on load capacity of the reinforced concrete. Service life predictions were reported for examples in which the concrete had a compressive strength of $20 \mathrm{MPa}$ and the yield strength of the steel was $400 \mathrm{MPa}$. Safety factors of 1.5 and 1.1 were used for concrete and steel design strengths, respectively. Fig. 2 shows the reduction of cross section as a function of bar diameter and corrosion rates. The predicted decrease in the bending moment capacity of reinforced concrete beams as a function of corrosion is shown in Fig. 3. Similar figures were constructed for shear and axial forces in beams. 
Based on the combination of laboratory, outdoor exposure, and field studies, Clear [15] suggested the use of the following relationships (which assume constant corrosion rates with time) between corrosion rates (Icorr) and remaining service life:

1). Icorr less than $0.5 \mu \mathrm{A} / \mathrm{cm}^{2}$ - no corrosion damage expected.

2). Icorr between 0.5 and $2.7 \mu \mathrm{A} / \mathrm{cm}^{2}$ - corrosion damage possible in the range of 10 to 15 years.

3). Icorr between 2.7 and $27 \mu \mathrm{A} / \mathrm{cm}^{2}$ - corrosion damage expected in 2 to 10 years.

4). Icorr in excess of $27 \mu \mathrm{A} / \mathrm{cm}^{2}$ - corrosion damage expected in 2 years or less.

These criteria appear to be in general agreement with the predictions given by Andrade.

Corrosion rates are affected by the temperature and moisture content of reinforced concrete [4]. If they vary, e.g., as with an exterior concrete surface, then the corrosion rates also will vary and a single corrosion measurement will not give reliable predictions. To overcome such problems, Andrade and co-workers [16], calculated an average corrosion rate over a year, similar to the way that atmospheric corrosion of steel is measured. They related corrosion rates of reinforcing steel to the humidity within concrete, as shown in Fig. 4. Using weather data, the internal humidity conditions are estimated over a specific period. An example of this approach is [16]: assuming that (1) the ambient relative humidity is below $70 \%$ during 4 months, (2) the relative humidity is between 70 and $100 \%$ during 6 months (1.0x6 factor in eq. (6)), and (3) rain occurs during 2 months. An estimate of the average corrosion rate, using data from Fig. 4, is:

$$
\frac{0.1 \times 4+1.0 \times 6+2 \times 10}{12}=2.2 \mu \mathrm{A} / \mathrm{cm}^{2}
$$

or $0.0253 \mathrm{~mm} /$ year.

If the average corrosion rate is known, then the time-to-crack can be estimated by following the method given by Cady and Weyers [17]. It involves transforming the average corrosion rate to an increase in diameter of the reinforcing bars. Then the stresses produced in the concrete can be roughly calculated using equations developed by Bazant [6] which relate stress development to the size of the corroding reinforcement, the mechanical properties of the concrete, diameter of reinforcement, and spacing of the reinforcement. Cracking will occur when the average tensile stress on the crack exceeds the tensile strength of the concrete. 


\section{PREDICTION BASED ON EXTRAPOLATION}

\subsection{Empirical Extrapolation}

The remaining service life of a concrete structure or element may be predicted by knowledge of its present condition and extrapolating to when it either needs extensive repair, restoration, or must be replaced. In the following, the need for extensive replacement of the existing concrete is considered to represent the end-of-life (EOL) condition. The extrapolation process is shown in Fig. 5A. The age of the concrete at the time of condition inspection (C.I.) is $t_{i}$, age at failure is $t_{f}$, and the remaining service life is $t_{r}=t_{f}-t_{i}$.

The problem is to make the proper extrapolation starting from the condition at inspection to the failure condition. To make the extrapolation, the amount of previous degradation needs to be determined. Often little information is available on the aging of the concrete. The only available information may be on the properties of the concrete when the structure is constructed and when the structure is inspected, i.e., two points. An induction period occurs in the degradation process (see Fig. 1) which could be disclosed by periodic inspections. Lack of knowledge of the existance of an induction period (I) or of when it ends will be manifested in a divergence of the predicted life $\left(t_{f}\right)$ compared to the predicted life when the induction period is considered $\left(\mathrm{t}_{\mathrm{f}}^{*}\right)$ (Fig. 5b). If the induction period is short compared to the propogation period then little error may be induced by neglecting it. The divergence $\left(\Delta t_{r}\right)$ will become more significant as the duration of the induction period increases.

\subsection{Time Order Concept}

Rather than making an empirical extrapolation, the time order approach gives a technical basis for the extrapolation. This approach has been used previously for diffusion processes, e.g., those involving depth of carbonation or chloride ion diffusion. In the following, we give a fundamental basis for the approach and generalize its application.

The amount of degradation of a concrete is dependent on the environment, geometry of the structure, properties of the concrete, the specific degradation processes, and the concentration of the aggressive specie(s). In the time order approach, it is assumed that these factors are invariant and thus can be represented by a constant, $k_{d}$ [2]. It is recognized that the climate changes from season to season but usually the variation between years smooths out over several decades. If this assumption is valid, then, only the number of service years need to be represented by the time function, $t_{y}$, and $k_{d}$ has an average value over the period considered. Implicit in this analysis is that the same degradation process(es) is active during the past and future life of the concrete.

In this approach, the amount of degradation, $A_{d}$, can be represented by [2]:

$$
A_{d}=k_{d} t_{y}{ }^{n}
$$


where $A_{d}$ is the amount of accumulative deterioration at time $t_{y}$ (years), and $\mathrm{n}$ is the time order. Note that if $\mathrm{n}=0$, there is no degradation.

If an induction period has occurred and its duration known, then the right hand side of eq. (7) would be $k_{d}\left(t_{y}-t_{o}\right)^{n}$, with $t_{o}$ being the duration of the induction period.

In the development of the approach, the term "time order" has been used to avoid confusion with the order of a chemical reaction, e.g., a second order reaction which can indicate that two molecules react together.

The overall rate of degradation, $R_{d}$ is given by:

$$
\mathrm{R}_{\mathrm{d}}=\mathrm{nk}_{\mathrm{d}} \mathrm{t}_{\mathrm{y}}^{\mathrm{n}-1}
$$

Equation (8) indicates that when $\mathrm{n}<1$, the rate of degradation decreases with time; when $\mathrm{n}$ $=1$, the rate is constant; and when $\mathrm{n}>1$, the rate increases with time.

Defining $A_{d f}$ as the amount of damage-at-failure, it follows from eq. (7) that:

$$
\mathrm{t}_{\mathrm{yf}}=\left(\mathrm{A}_{\mathrm{df}} / \mathrm{k}_{\mathrm{d}}\right)^{1 / \mathrm{n}}
$$

where $t_{\mathrm{yf}}$ is the time to failure. The remaining service life is obtained by subtracting the age of the concrete when the inspection was made from $t_{y f}$.

\subsection{Value of $n$}

The value of $\mathrm{n}$ depends on the rate controlling process. It can be obtained by a theoretical analysis of rate controlling processes, by mathematical modeling of degradation processes, and empirically from accelerated degradation tests.

\subsubsection{Theoretical Values of $\mathrm{n}$ for Diffusion and Reaction Control}

The theoretical determination of $\mathrm{n}$ for reaction and diffusion is carried out based on the model system represented in Fig. 6. The concrete element has thickness L, and is initially exposed on one side to a constant concentration, $\mathrm{C}_{\mathrm{Ao}}$, of ions of species A. Species A represents any dissolved chemical species capable of reacting with the solid constituents of the concrete. It is assumed that transport only occurs in the $\mathrm{x}$ direction. The interface between the degraded and undegraded zones is located at $\mathrm{x}_{\mathrm{i}}$. The concentration of $\mathrm{A}$ at the interface is $\mathrm{C}_{\mathrm{Ai}}$. The concrete is initially saturated, and remains saturated with pore water as the concrete degrades. 
The effects of convection or flow are not considered as convection effects are negligible for dense concrete subject to low to moderate hydraulic gradients. The conditions under which convection becomes an important transport mechanism in concrete have been discussed by Pommersheim and Clifton [18].

Under this scenario, diffusion and reaction become the dominant transport mechanisms. The degradation processes considered are represented by the reaction:

$$
\mathrm{A}+\mathrm{bB}(\mathrm{s}) \rightarrow \mathrm{e} E(\mathrm{~s})
$$

where $B$ is the solid component of the concrete which reacts with $A$ and $E$ is the product; $b$ and $e$ are stoichiometric coefficients; and $b$ is the molar ratio of $B$ to A consumed by the reaction.

The interface position $\left(x_{i}\right)$ is dependent on the rate of molar consumption of solid $B$ in the concrete, and is given by:

$$
\text { b } \rho_{B} S f_{B} \frac{d x_{i}}{d t}=N_{A} S
$$

where $\rho_{B}$ is the molar density of $B, S$ is the total cross-sectional area of the element, $f_{B}$ is the volume fraction of $B$ in the concrete and $N_{A}$ is the molar flux of reactant $A$.

At quasi-steady state the molar flow of A will be constant and, since the total area does not change, the flux is also constant. The flux is given by Fick's first law:

$$
N_{A}=-D_{A e} \frac{d_{A}}{d x}
$$

where $D_{A e}$ is the effective diffusion coefficient of $A$ through the pores of the degraded zone.

Integrating eq. (12) between the outside surface of the concrete $(x=0)$ and the interface $\left(\mathrm{x}=\mathrm{x}_{\mathrm{i}}\right)$ gives:

$$
N_{A}=D_{A e}\left(C_{A o}-C_{A i}\right) / x_{i}
$$

Eq. (13) predicts a linear concentration profile through the element as depicted in Fig. 6 by the dashed curve. For most degradation mechanisms the gradient will be negative. An 
exception is leaching of calcium hydroxide by groundwater where $\mathrm{C}_{\mathrm{Ao}}=0$ and $\mathrm{C}_{\mathrm{Ai}}$ is the saturation concentration of calcium hydroxide in the pore water.

Equating the diffusion flux to the surface reaction rate, $-\mathrm{r}_{\mathrm{As}}$ :

$$
\mathrm{N}_{\mathrm{A}}=-\mathrm{r}_{\mathrm{As}}=\mathrm{k}_{\mathrm{s}} \mathrm{C}^{*}{ }_{\mathrm{B}} \mathrm{C}_{\mathrm{Ai}}=\mathrm{D}_{\mathrm{Ae}}\left(\mathrm{C}_{\mathrm{Ao}}-\mathrm{C}_{\mathrm{Ai}}\right) / \mathrm{x}_{\mathrm{i}}
$$

where $k_{s}$ is the surface reaction velocity constant and $C_{B}{ }^{*}$ is the saturation concentration of solid $\mathrm{B}$ in equilibrium with the pore water in the undegraded zone.

In this formulation, it is presumed that the reaction is second order overall, first order with respect to $\mathrm{A}$ and $\mathrm{B}$, and that $\mathrm{B}$ is present at the interface in molar excess. Under these conditions $C_{B}{ }^{*}$ will be constant. Solving eq. (14) for $C_{A i}$ :

$$
\mathrm{C}_{\mathrm{Ai}}=\frac{\mathrm{C}_{\mathrm{Ao}}}{1+\frac{\mathrm{k}_{\mathrm{S}} \mathrm{C}_{\mathrm{B}}{ }^{*} \mathrm{x}_{\mathrm{i}}}{\mathrm{D}_{\mathrm{Ae}}}}
$$

By substituting eq. (15) into eq. (13) for $C_{A i}$, replacing $N_{A}$ by the right hand side of eq. (13), and integrating, the following result is obtained:

$$
x_{i}+\frac{k_{S} C_{B} *}{2 D_{A e}} x_{i} 2=\frac{k_{S} C_{B} * C_{A o}}{b f_{B} \rho_{B}} t
$$

Eq. (16) predicts the location of the interface between the degraded and undegraded zones as a function of time. It has two important subcases, reaction control and diffusion control. Which process controls depends on the magnitude of the reaction-diffusion modulus $\mathrm{m}$ defined by:

$$
m=\frac{k_{S} C_{B} * L}{D_{A e}}
$$

The modulus $\mathrm{m}$ is a dimensionless constant which measures the relative magnitude of diffusion and reaction. It is a function of the reactivity as measured by the surface reaction constant $k_{s}$, the saturation concentration of the solid $C_{B}{ }^{*}$, the slab thickness $L$, and the effective diffusivity $\mathrm{D}_{\mathrm{Ae}}$ of ions through the pores of the concrete. Reaction is likely to 
control at small values of $m(m<<1)$ while diffusion control is likely at high values of $m$ $(\mathrm{m}>>1)$. For moduli on the order of unity, neither reaction nor diffusion controls.

Eq. (16) can be put in dimensionless form using eq. (17):

$$
Y_{i}+\frac{m}{2} Y i^{2}=\frac{t}{\tau}
$$

where $Y_{i}$ is the dimensionless coordinate $x_{i} / L$ and $\tau$ is a time constant given by:

$$
\tau=\frac{b \rho_{B} f_{B}}{C_{A 0}} \frac{L}{k_{s} C_{B}^{*}}
$$

$\tau$ is a measure of the rate that the interface moves through the concrete. High values mean that the interface is moving slowly.

The rate controlling process can be determined by analyzing the limit forms of eq. (18) at both high and low values of $m$. At low values of $m$ the expression reduces to:

$$
Y_{i}=\frac{t}{\tau}
$$

This is the reaction controlled limit which predicts that the interface $x_{i}$ will move in linearly with time. Equation (20) is of the form:

$$
x_{i} \propto t^{n}, \quad \text { with } n=1
$$

At high values of $\mathrm{m}$, the reaction is diffusion controlled and eq. (22) is obtained:

$$
Y_{i}=\left(\frac{2 t}{\tau}\right)^{1 / 2}
$$

Therefore, eq. 22 is of the form: 


$$
\mathrm{x}_{\mathrm{i}} \propto \mathrm{t}^{\mathrm{n}} \quad \text { with } \mathrm{n}=1 / 2
$$

Comparing these results to the time order approach shows that the limits of $\mathrm{n}=1$ and $\mathrm{n}=$ $1 / 2$ correspond, respectively, to reaction (eq. 21) and diffusion (eq. 23) control.

\subsubsection{Values of $n$ Based on Mathematical Models}

Values of $\mathrm{n}$ can also be obtained from an analysis of the form of mathematical models as demonstrated in the following for sulfate attack. A mechanistic model has been developed [19] for predicting the effect of sulfate attack on service life of concrete. The model is based on following assumptions:

(1) sulfate ions from the environment penetrate the concrete by diffusion,

(2) sulfate ions react expansively with aluminate in the concrete, and

(3) cracking and delamination of concrete surfaces result from the expansive reactions.

The rate of degradation $(\mathrm{R})$ is given by (19):

$$
\mathrm{R}=\mathrm{X}_{\text {spall }} / \mathrm{T}_{\text {spall }}=\left(\mathrm{EB}^{2} \mathrm{c}_{\mathrm{s}} \mathrm{C}_{\mathrm{o}} \mathrm{D}_{\mathrm{i}}\right) / \alpha_{\mathrm{o}} \tau(1-v)
$$

where $X_{\text {spall }}$ is the thickness of a spalled layer,

$\mathrm{T}_{\text {spall }}$ is the time for a layer to spall,

$\mathrm{E}$ is Young's modulus,

$B$ is the linear strain caused by one mole of sulfate, reacted in $1 \mathrm{~m}^{3}$ of concrete, $\mathrm{C}_{\mathrm{s}}$ is the sulfate concentration in the bulk solution, $\mathrm{C}_{\mathrm{o}}$ is the concentration of reacted sulfate present as ettringite,

$D_{i}$ is the intrinsic diffusion coefficient of sulfate ions, $\alpha_{0}$ is a roughness factor for the fracture path (assumed to be 1.0),

$\tau$ is the fracture surface energy of concrete, and

$v$ is Possion's ratio.

Analysis of the equation indicates that the depth of degradation with rate is linear in time $(\mathrm{m} / \mathrm{s})$ and thus $\mathrm{n}=1$.

Some values of $\mathrm{n}$ obtained from models are given in Table 1 [2]. Degradation versus time relationships for $n=1 / 2,1$ and 2 are shown in Fig.. 7. The relationships with $n=1 / 2$ and 1 are frequently found. A value of $n>1$ may occur if the degradation process is controlled by volumetric increases induced by microcracking. 


\subsubsection{Value of $n$ Obtained from Accelerated Degradation Studies}

The value of $n$ may be obtained from accelerated degradation testing. An important requirement for using accelerated testing for determining $n$ is that the degradation mechanism in the accelerated test be the same as that responsible for the in-service deterioration.

Expressing eq. 7 logarithmically:

$$
\log A_{d}=\log k_{d}+n \log t_{y}
$$

Based on this equation, the value of $n$ can be determined by plotting the log of the accumulative degradation vs. the log of test time, as shown in Fig. 8. The slope of the plot is $n$. The value of $k_{d}$ can be found from any point on the plotted line. When an induction period is present, $t_{y}$ in eq. (25) should be replaced by $\left(t_{y}-t_{I}\right)$, where $t_{I}$ is the induction period.

By obtaining $\mathrm{n}$ from accelerated degradation testing the validity of mathematical models of degradation rates can be tested. Studies are currently being carried out at NIST to determine if sulfate attack has a time order of unity.

Table 1. Values of $\mathrm{n}$ Obtained from Models [2]

Degradation Process

carbonation

diffusion of chloride ions

acid attack (siliceous aggregate)

acid attack (carbonate aggregate)

sulfate attack

frost attack

active corrosion of steel reinforcement (propagation)
Value of $n$

$1 / 2$

$1 / 2$

$1 / 2$

1

1

1

1 


\subsection{Example of Application of Method}

The value of $n$ is known to be $1 / 2$ for carbonation [20] and the remaining service life of reinforced concrete, considering only the initiation period, is easily obtained from knowledge of the age of the concrete, the depth of carbonation, and the depth of the reinforcing steel. The depth of carbonation can be obtained using a phenolphthalein indicator solution and the depth of the reinforcing steel measured during inspection. If the average depth of carbonation was $24 \mathrm{~mm}$ after 36 years and the average concrete cover over the reinforcing bars was 48 $\mathrm{mm}$, from eq. (7) $\mathrm{k}_{\mathrm{d}}$ would be:

$$
\mathrm{k}_{\mathrm{d}}=\mathrm{A}_{\mathrm{d}} / \mathrm{t}_{\mathrm{y}}{ }^{\mathrm{n}}=24 / 36^{1 / 2}=4 \mathrm{~mm} / \mathrm{y}^{1 / 2},
$$

and substituting the value for $k_{d}$ in eq. (9) gives the time-to-failure $t_{y f}$ :

$$
\mathrm{t}_{\mathrm{yf}}=(48 / 4)^{2}=144 \text { years. }
$$

Since the concrete was 36 years old at the time of inspection, the predicted remaining service life would be around 108 years.

If it was assumed that $n=1$, then it follows that:

$$
\mathrm{k}_{\mathrm{d}}=\mathrm{A}_{\mathrm{d}} / \mathrm{t}_{\mathrm{y}}^{\mathrm{n}}=24 / 36=0.67 \mathrm{~mm} / \mathrm{y} \text {, }
$$

so that:

$$
\mathrm{t}_{\mathrm{yf}}=(48 / 0.67)=72 \text { years, }
$$

and the predicted remaining service life would be 36 years.

In the same way, if it is assumed that $\mathrm{n}=2$, then:

$$
\mathrm{k}_{\mathrm{d}}=\mathrm{A}_{\mathrm{d}} / \mathrm{t}_{\mathrm{y}}{ }^{\mathrm{n}}=24 / 36^{2}=0.0186 \mathrm{~mm} / \mathrm{y}^{2},
$$

and

$$
\mathrm{t}_{\mathrm{yf}}=(48 / 0.0186)=51 \text { years, }
$$

with a predicted remaining life of only 15 years. These results indicate the importance of properly determining the value of the time order $n$.

Several forms of the depth of carbonation and the depth of the concrete cover over the reinforcement could be used including average depth, minimum depth, and maximum depth. 
If the distribution in the depth of carbonation and the depth of cover of concrete over the reinforcement were known, a probabilistic distribution of remaining life could be estimated.

The model used by Browne [7] for predicting the remaining service life of in-service reinforced concrete structures exposed to chloride ions, follows a somewhat similar approach to that used in the carbonation example. The chloride ion diffusion coefficient is first determined based on analyzing specimens of the concrete taken from different locations for chloride contents. Then the diffusion coefficient is used to estimate the time for the threshold concentration (corrosion inducing concentration) of chloride ions to reach the depth of the reinforcement, which is taken to represent the end of the service life of the concrete.

\subsection{Dealing with Cyclic Degradation Processes}

The effect of degradation processes which involve distinct cyclic events may be predicted based on estimating the number of past degradation cycles to which concrete has been subjected. For example, frost attack occurs when concrete is both critically saturated and simultaneously exposed to freezing temperatures. If local weather data is available for the past service years of the concrete, the number of times the concrete was exposed to freezing temperatures could be estimated and correlated with the amount of degradation. Then assuming that the future temperature patterns follow past patterns, the years required to reach failure could be predicted. The applicability of this model could possibly be increased by developing probabilistic methods for dealing with fuzzy weather data, e.g., weather data which is from a sufficiently remote source so that the degree of correlation with the microclimate of the concrete is not known with high certainty, or if weather data is available for only a part of the concrete's past service life.

\subsection{Applicability to Multi-Degradation Processes}

Two or more degradation processes occurring simultaneously, with different time orders and no predominant rate controlling process, should be treated by using the highest time order. This will give the minimum life and represent a conservative approach. For example if the depth of penetration by diffusion of chloride ions and the depth of sulfate attack are moving at nearly the same rate, let $\mathrm{n}=1$ in eq. (8).

\section{PREDICTIONS BASED ON ESTIMATING ORIGINAL SERVICE LIFE}

Situations may be encountered in which the remaining service life of concrete can only be estimated by predicting its original life using a service-life model, such as described in ref. [2]. Such a situation could arise where the concrete can not be inspected or samples could not be taken due to its inaccessibility or to potential serious hazards involved with its inspection. This would necessitate obtaining or estimating the values of materials properties required to solve the model, e.g., diffusion coefficients for chloride ions. It is unlikely that all the required data would be available, especially data on transport properties of the 
concrete. Useful data probably could be obtained by testing concrete specimens which are prepared using the same mix proportions and curing conditions as reported for the in-service concrete. As a last resort, data from the characterization of a similar existing or demolished concrete structure could be judiciously chosen for input into the models. After the required data is obtained, the appropriate service-life model could be solved. The predicted original life minus the age of the concrete would give its estimated remaining service life. Obviously, this is not a desirable approach for predicting remaining service lives because of the large uncertainties which invariably would be associated with the estimates. Nevertheless, it provides a reasonable approach when data can not be directly obtained by inspecting either a structure or some of its critical concrete elements.

\section{SUMMARY}

The ability to predict the remaining life of concrete structures is becoming increasingly important as the nation's infrastructure ages. Decisions on whether to repair or to demolish structures may depend on the estimated remaining life. Little attention has been given to developing methods for predicting remaining service lives, with most of the reported work dealing with corrosion of concrete reinforcement. These methods primarily involved the use of mathematical models and life-time extrapolations based on corrosion current measurements.

Predicting remaining service life usually involves making some type of time extrapolation from the present state of the concrete to the end-of-life state. The application of the time order concept in making time extrapolations is described in this report. Also, ways to determine the value of $\mathrm{n}$ (time order) in the time function $\mathrm{t}^{\mathrm{n}}$ of degradation rate relationships are given. They include the analysis of mathematical models and accelerated degradation tests. For example, analysis of a sulfate degradation model indicates that the rate of degradation by sulfate attack is linear with time, i.e., $n=1$. Modeling of rate controlling mechanisms in degradation processes indicate that if the reaction is diffusion controlled $n=$ $1 / 2$, or $\mathrm{n}=1$ if the process is reaction controlled. Use of the time order approach is demonstrated for $n=1 / 2,1$, and 2 . Ways to apply the approach to cyclic processes and multi-degradation processes are discussed.

Situations may be encountered in which the remaining service life of concrete can only be estimated by predicting its original life using a service-life model. Such a situation could arise where the concrete can not be inspected or samples taken due to its inaccessibility or to potential serious hazards involved with its inspection. This would necessitate obtaining or estimating the values of the materials properties required to solve the model, e.g., diffusion coefficients for chloride ions. After the required data is obtained, the appropriate service-life model could be solved. The predicted original life minus the age of the concrete would then predict its estimated remaining service life. 


\section{REFERENCES}

1. D.J. Naus, "Concrete Component Aging and Its Significance Relative to Life Extension of Nuclear Power Plants," NUREG/CR-4662, U.S. Nuclear Regulatory Commission, Washington, D.C. (1986).

2. J.R. Clifton, "Predicting the Remaining Service Life of Concrete," NISTIR 4712, National Institute of Standards and Technology (1991).

3. C.J. Hookham, "Rehabilitation of Great Lakes Steel's No. One Dock, " ACI Symposium of Durability of Concrete, in press.

4. K. Tuutti, "Corrosion of Steel in Concrete," Swedish Cement and Concrete Research Institute, Stockholm (1982).

5. Z.P. Bazant, "Physical Model for Steel Corrosion in Concrete Sea StructuresTheory," ASCE Journal of the Structures Division, Vol. 105 (ST6), 1137- 1153 (June 1979).

6. Z.P. Bazant, "Physical Model for Steel Corrosion in Concrete Sea StructuresApplication," ASCE Journal of the Structures Division, Vol. 105 (ST6) 1155-1166 (June 1979).

7. R.D. Browne, "Mechanisms of Corrosion of Steel in Concrete," in Concrete in Relation to Design, Inspection, and Repair of Offshore and Coastal Structures, ACI SP-65.

8. E. Vesikari, "Service Life of Concrete Structures with Regard to Corrosion of Reinforcement," Technical Research Centre of Finland Research Report No. 553 (Espoo, August 1988).

9. H. Klopper, "Carbonation of External Concrete and How to Combat It," Bentenschutz and Bausanierung, Vol. 1, No. 3 (1978).

10. R.F.M Bakker, "Initiation Period," Chapter Three in Corrosion of Steel in Concrete, ed. P. Schiessel, Chapman and Hall, New York, 1988.

11. D.C. Pocock, "Prediction of Possible Reinforcement Corrosion during Remaining Life in Concrete Structures at Nuclear Installations," Symposium on the Review of Safety at Magnox Nuclear Installations, London (March 9, 1989).

12. J.R. Rodriquez and C. Andrade "Load-Bearing Capacity Loss in Corroding Structures," presented at ACI 1990 Spring Convention, Toronto, in press. 
13. C. Andrade, C. Alonso, J.A. Gonalez, and J. Rodriguez, "Remaining Service Life of Corroding Structures," IABSE Report 57/1, Durability of Structures, 359-364 (1989).

14. C. Andrade, M.C. Alonso, and J.A. Gonzales, "An Initial Effort to Use the Corrosion Rate Measurements for Estimating Rebar Durability," ASTM STP Corrosion Rates of Steel in Concrete, pp. 29-37 (1990).

15. K. Clear, "Measuring Rate of Corrosion of Steel in Field Concrete Structures," Paper No. 88-0324, 68th Annual Meeting of Transportation Research Meeting (1989).

16. C. Andrade, C. Alonso, and J.A. Gonzalez, "Approach to the Calculation of the Residual Life in Corroding Concrete Reinforcement based on Corrosion Intensity Values," 9th European Congress on Corrosion: Life Time Expectancy of Materials and Constructions, Vol. 2, Ultrect, Netherlands (October 1989).

17. P.D. Cady and R.E. Weyers, "Deterioration Rates of Concrete Bridge Decks," Journal of Transportation, ASCE, Vol. 110, pp. 34-44 (1984).

18. Pommersheim, and J.R. Clifton, "Models of Transport Processes in Concrete," NISTIR 4405, National Institute of Standards and Technology (1990).

19. A. Atkinson and J.A. Herne, "Mechanistic Model for the Durability of Concrete Barriers Exposed to Sulphate-Bearing Groundwaters," Materials Research Society Symposium Proceedings 176, pp. 149-156 (1990).

20. R. Turriziani, "Internal Degradation of Concrete: Alkali-Aggregate Reaction. Reinforcement Steel Corrosion," 8th International Symposium on Chemistry of Cement, Vol 1, 388-442 (Rio de Janeiro, 1986). 


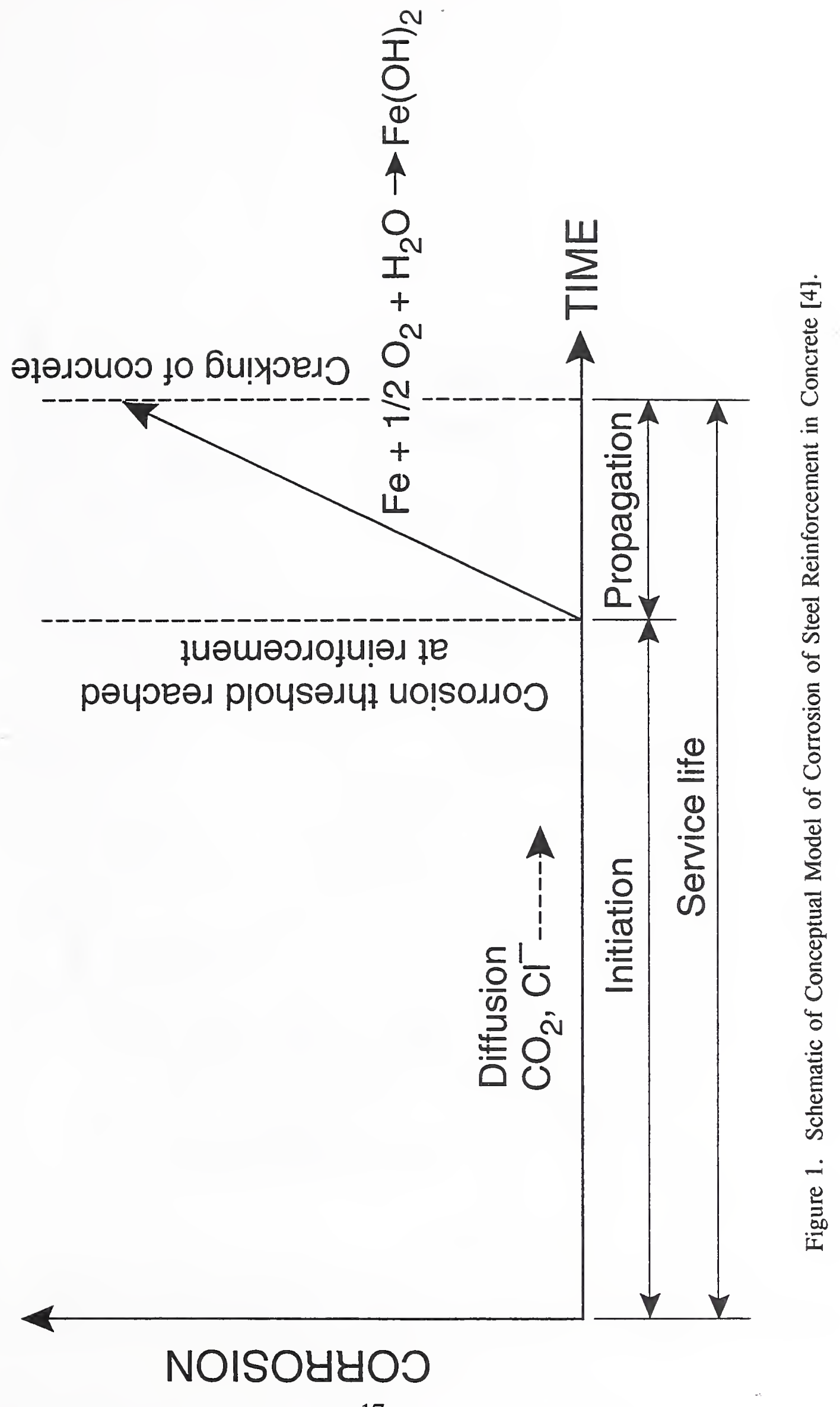



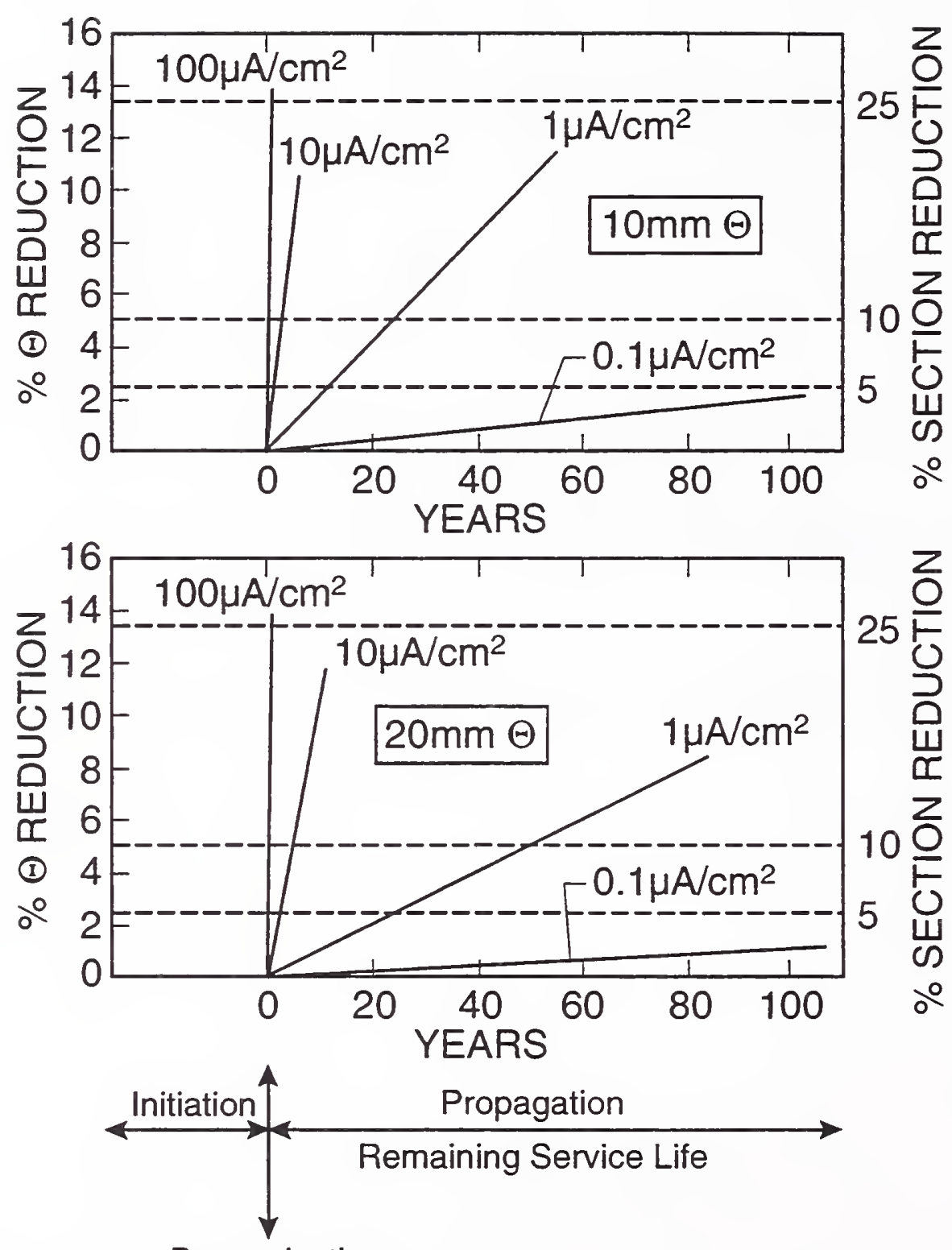

Depassivation

Figure 2. Effect of Corrosion on the Diameter $\Theta$ and Cross Section of Steel Reinforcing Bars, with Diameters of $10 \mathrm{~mm}$ and $20 \mathrm{~mm}$ [14]. 


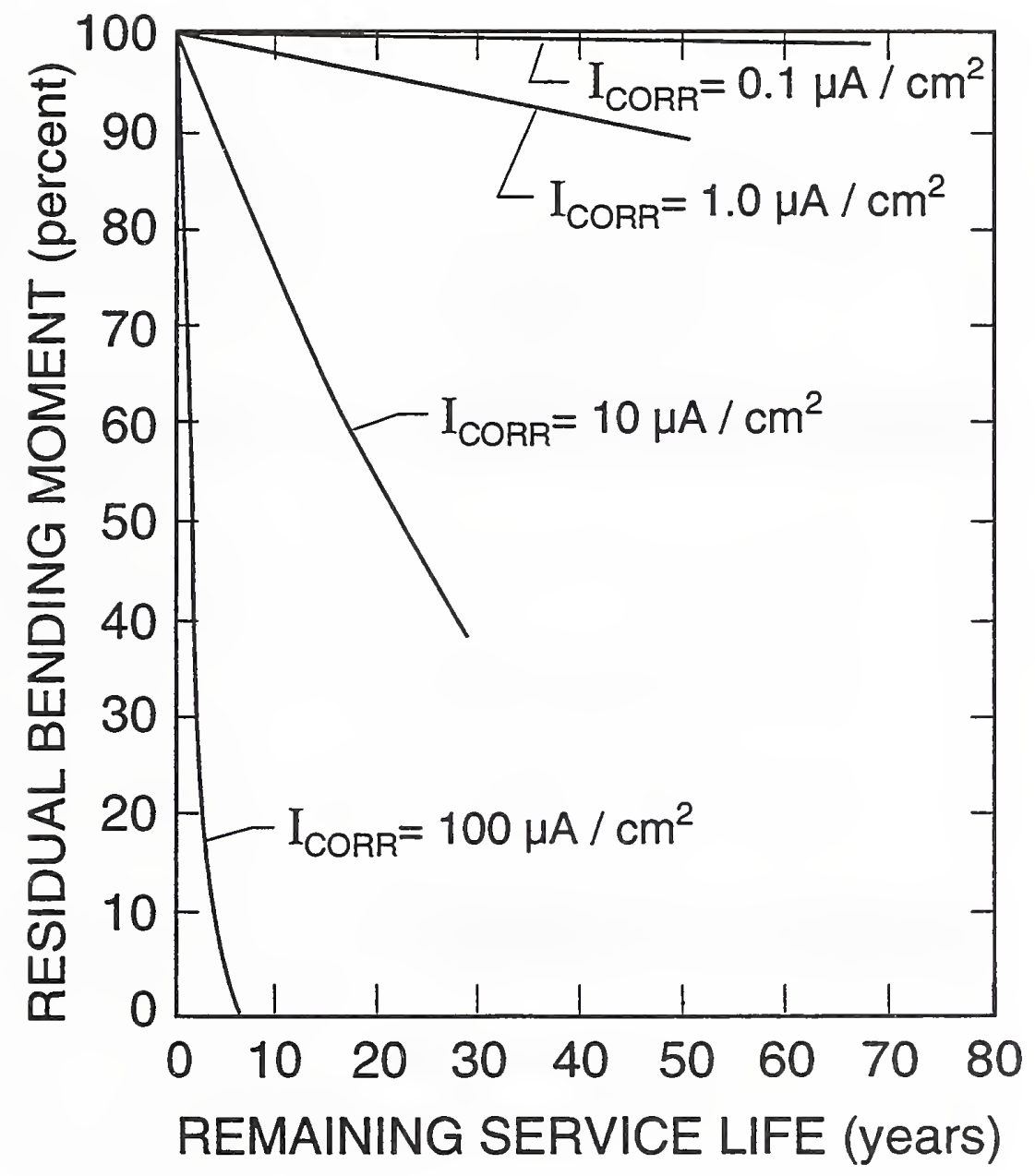

Figure 3. Reduction in Bending Moment Capacity of Concrete Beam by Corrosion of Reinforcing Steel [4]. 


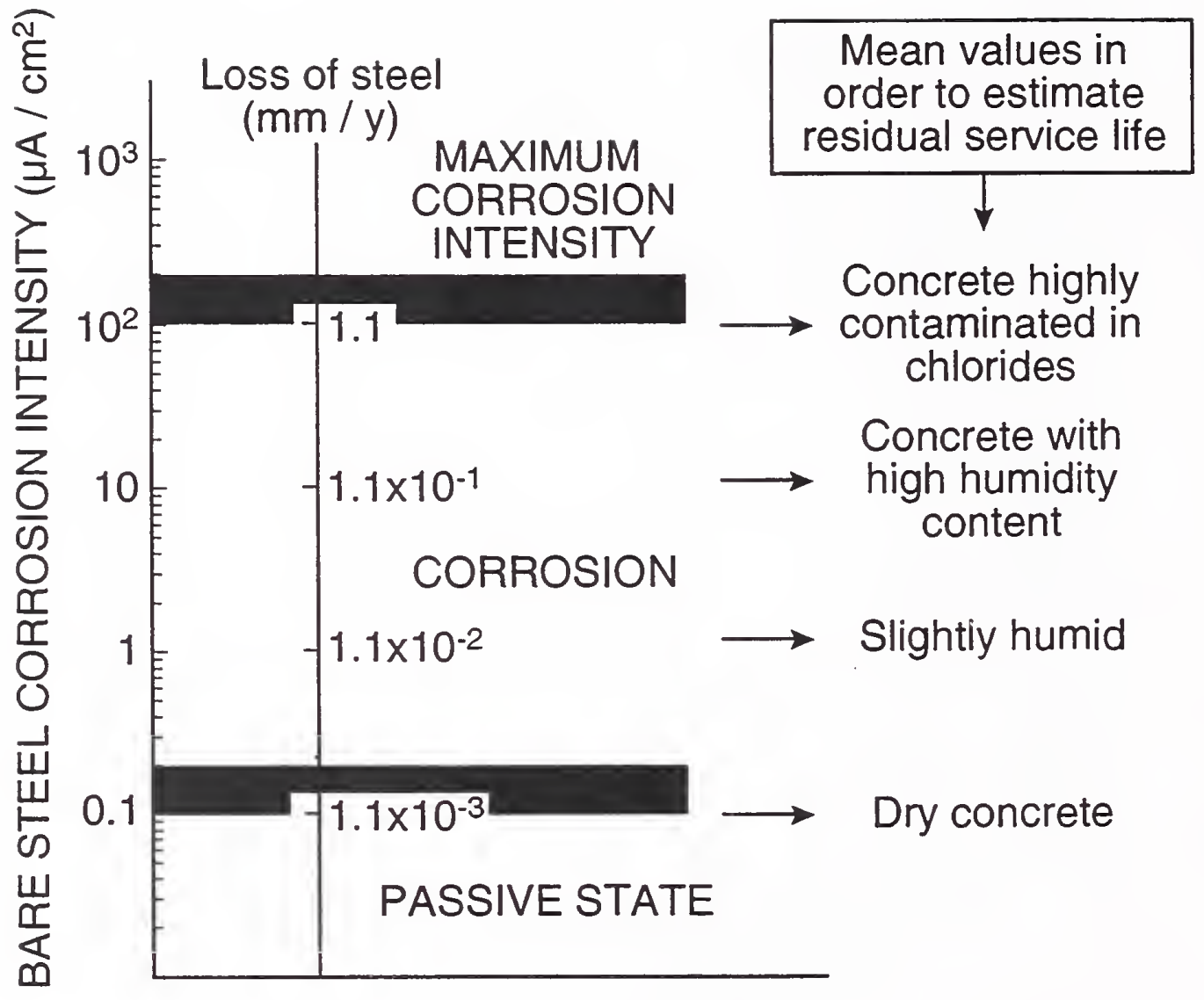

Figure 4. Relationship Between Corrosion Intensity (Current) of Steel Reinforcement and Concrete Environment [16]. 


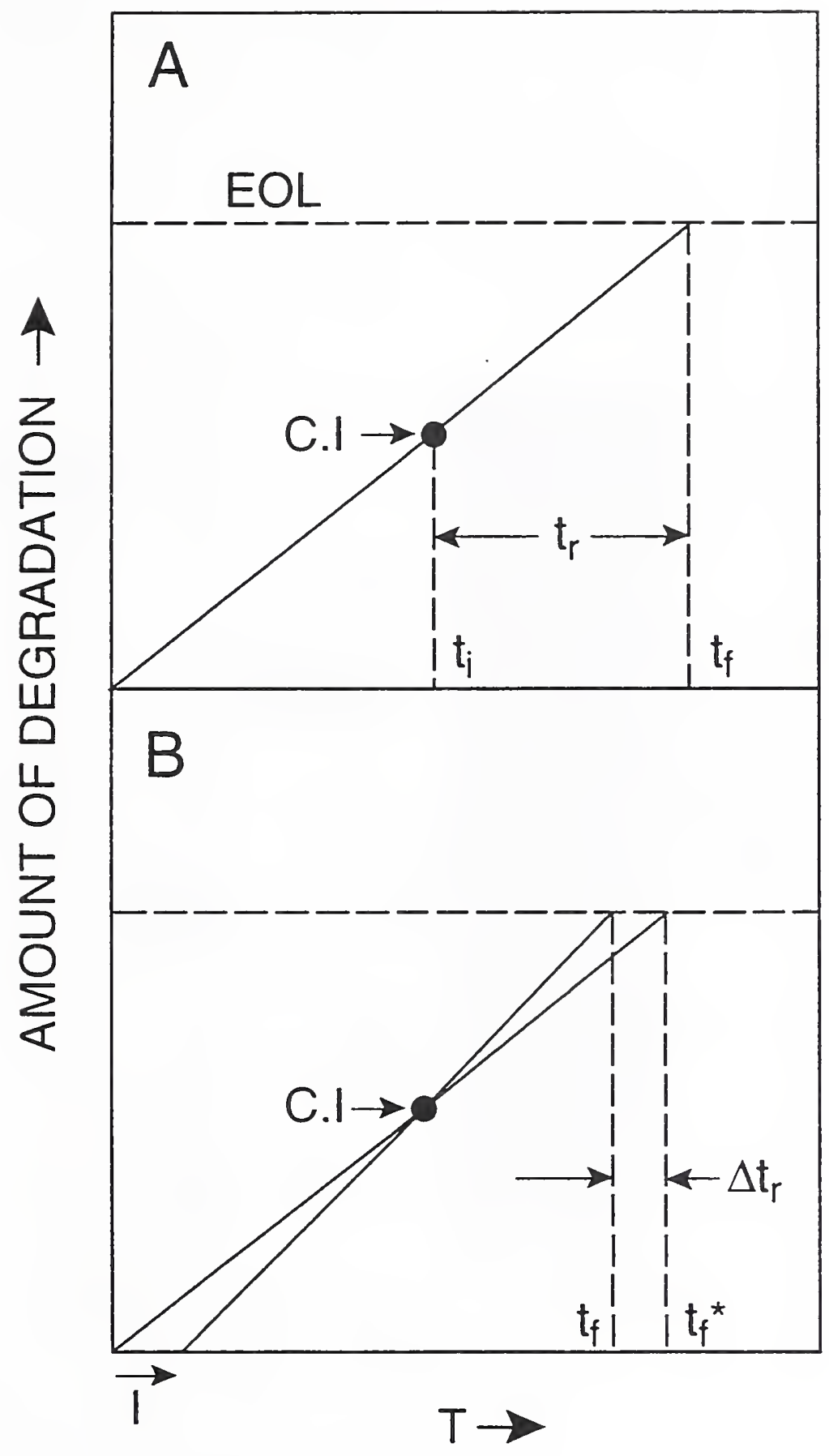

Figure 5. A. Schematic of Predicting Remaining Service Life by Extrapolation.

B. Effect of Neglecting Induction Period on Predicting Remaining Life. 


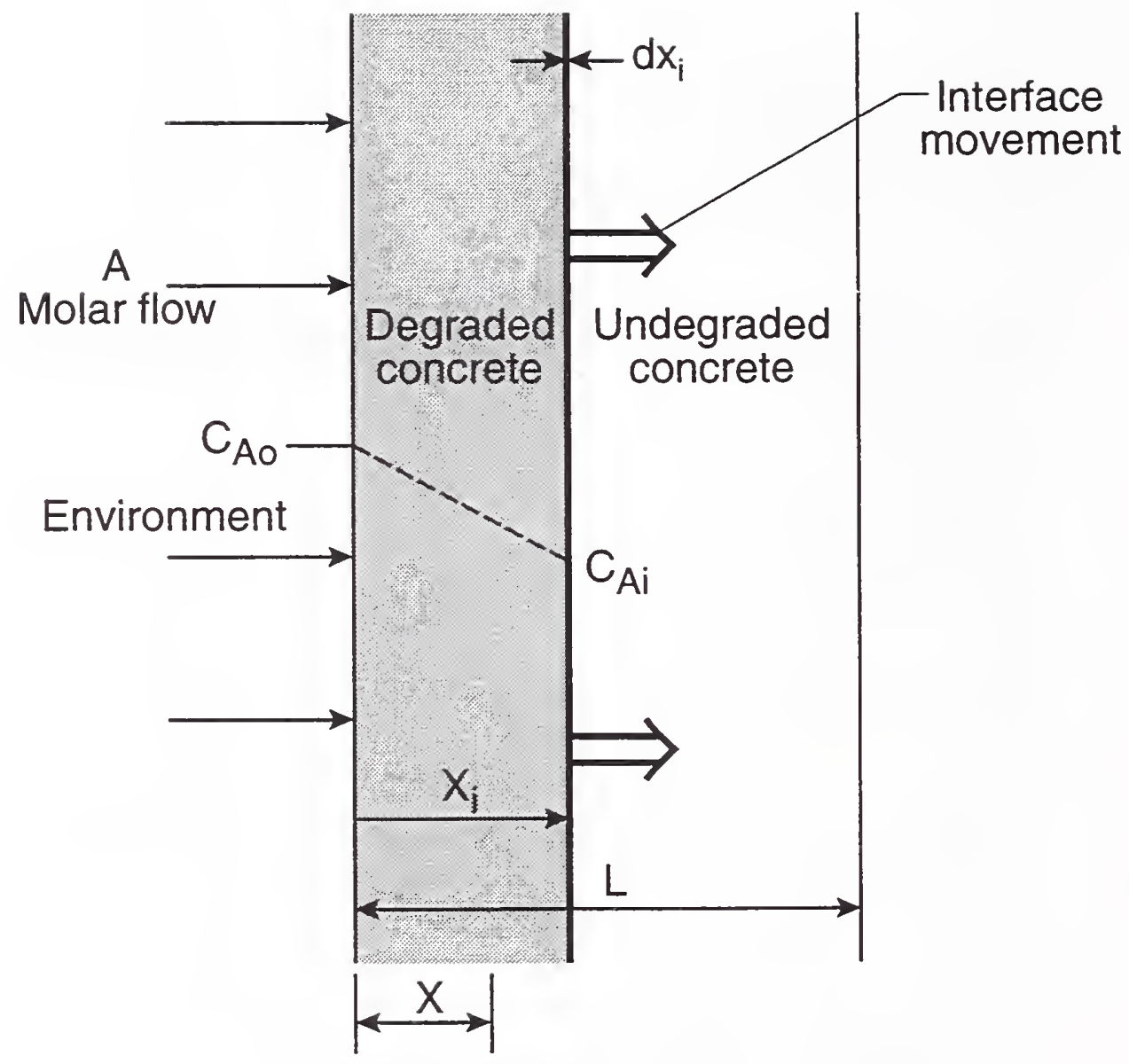

Figure 6. Schematic of Conceptual Model of Moving Interface Between Degraded and Undegraded Concrete. 


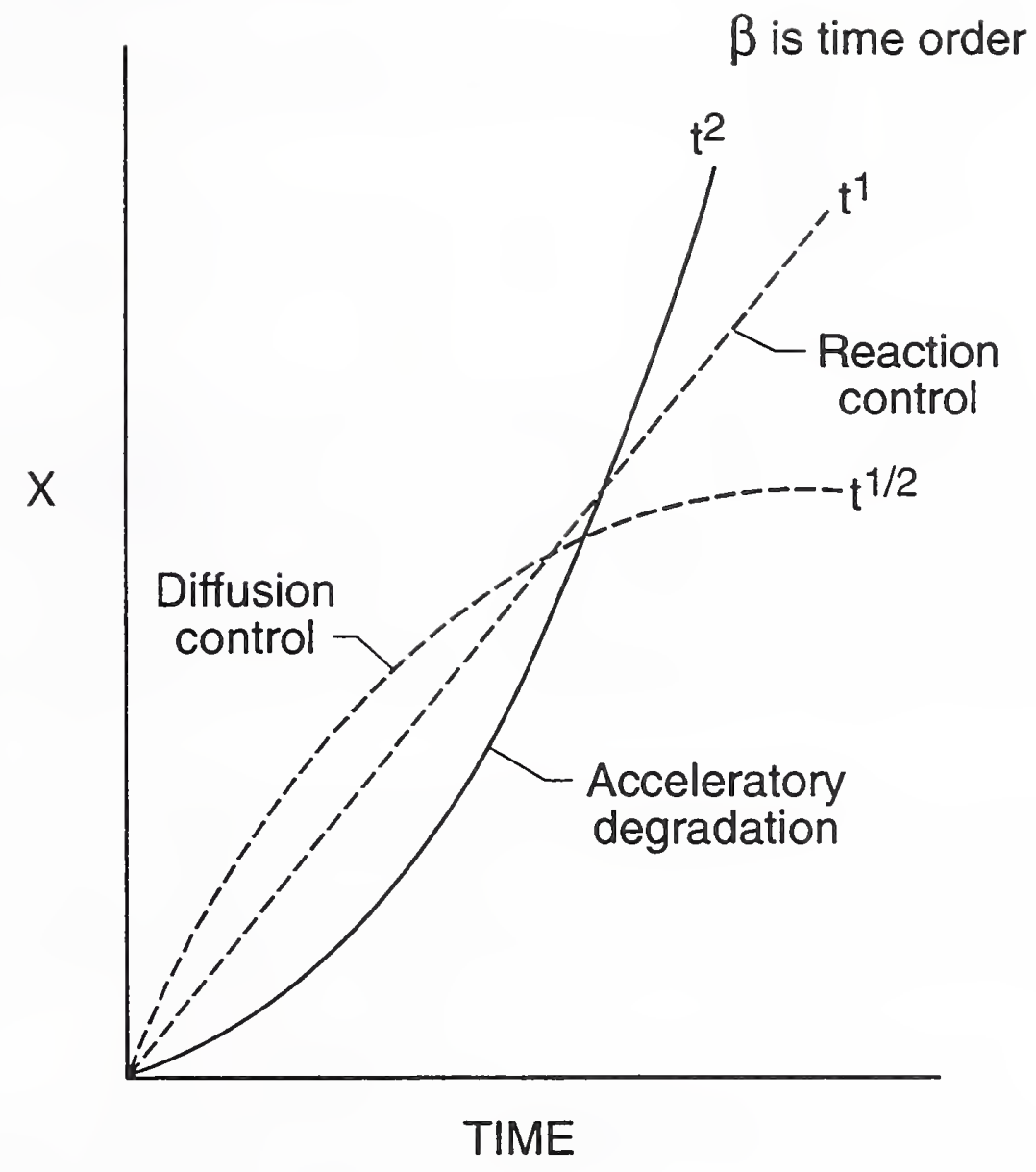

Figure 7. Degradation Versus Time Relationships of $n=1 / 2,1$ and 2 . 


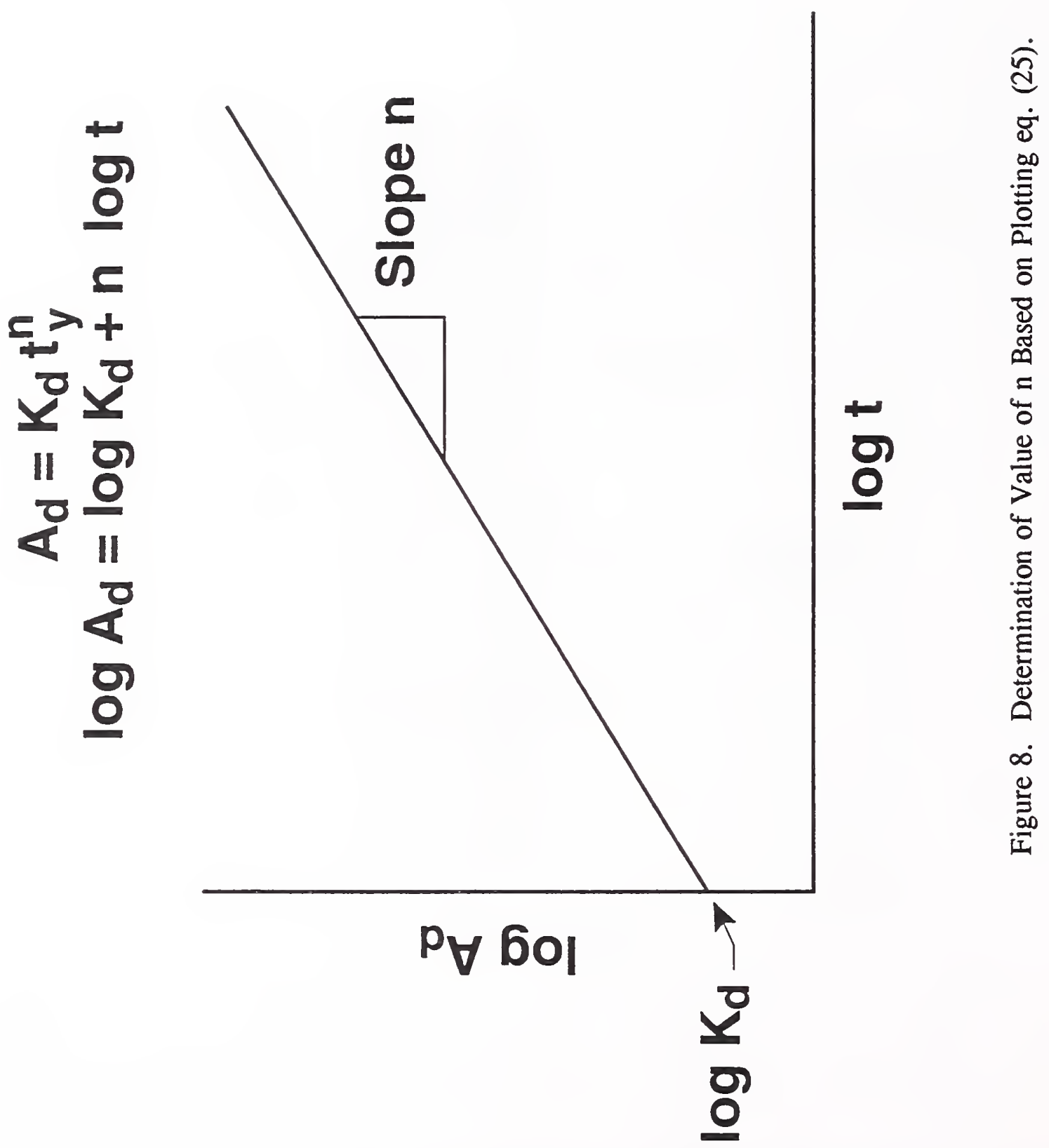




\section{NIST-114A \\ (REV. 3-90) \\ U.S. DEPARTMENT OF COMMERCE NATIONAL INSTITUTE OF STANDARDS AND TECHNOLOGY \\ BIBLIOGRAPHIC DATA SHEET}

\begin{tabular}{|l|l|} 
1. & $\begin{array}{c}\text { PUBUCATION OR REPORT NUMBER } \\
\text { NISTIR } 4954\end{array}$ \\
\hline 2. & PERFORMINO ORGAMIZATION REPORT NUMBER \\
\hline 3. & $\begin{array}{c}\text { PUBUCATION DATE } \\
\text { NOVEMber } 1992\end{array}$ \\
\hline
\end{tabular}

4. TITLE AND SUBTITLE

Methods for Predicting Remaining Life of Concrete in Structures

5. AUTHOR(S)

James R. Clifton and James Pommersheim

6. PERFORMING ORGANIZATION (IF JOINT OR OTHER THAN NIST, SEE INSTRUCTIONS)

U.S. DEPARTMENT OF COMMERCE

NATIONAL INSTITUTE OF STANDARDS AND TECHNOLOQY

GAITHERSBURG, MD 20899

7. CONTRACT/GRANT NUMBER

8. TYPE OF REPORT AND PERIOD COVERED

9. SPONSORING ORGANIZATION MAME AND COMPLETE ADDAESS (STREET, CITY, STATE, ZIP)

11. ABSTRACT (A 200-WORD OR LESS FACTUAL SUMMARY OF MOST SIGNIFICANT INFORMATION. IF DOCUMENT INCLUDES A SIGNIFICANT BIBUOGAAPHY OA LTERATURE SURVEY, MENTION IT HERE)

The ability to predict the remaining life of concrete structures is becoming increasingly important as the nation's infrastructure ages. Decisions on whether to repair or to demolish structures may depend on the estimated remaining life. Little attention has been given to developing methods for predicting remaining service lives, with most of the reported work dealing with corrosion of concrete reinforcement. These methods primarily involve the use of mathematical models and life-time extrapolations based on corrosion current measurements.

Predicting remaining service life usually involves making some type of time extrapolation from the present state of the concrete to the end-of-life state. The application of the time order concept in making time extrapolations is described in this report. Also, ways to determine the value of $\mathrm{n}$ (time order) in the time function $\mathrm{t}^{\mathrm{n}}$ of degradation rate relationships are given. Use of the time order approach is demonstrated for $\mathrm{n}$ $=1 / 2,1$, and 2 . Ways to apply the approach to cyclic processes and multi-degradation processes are also discussed.

Situations may be encountered in which the remaining service life of concrete can only be estimated by predicting its original life using a service-life model. Such a situation could arise where the concrete can not be inspected or samples taken, due to its inaccessibility or to potential serious hazards involved with its inspection. An approach for applying this method is discussed.

12. KEY WORDS (6 TO 12 ENTRIES; ALPHABETICAL ORDER; CAPITALIZE ONLY PROPER NAMES; AND SEPARATE KEY WORDS BY SEMICOLONS)

building technology; concrete; corrosion; diffusion; reaction controlled; reinforcement; remaining service life; service life; time order

\section{AVAILABILTY}

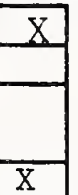

FOR OFFICIAL DISTAIBUTION. DO NOT RELEASE TO MATIOMAL TECHNICAL INFORMATION SERVICE (NTIS). ORDER FROM SUPERINTENDENT OF DOCUMENTS, U.S. GOVERMMENT PRINTING OFFICE, WASHINGTON, DC 20402. 


